\title{
Analisis Daerah Lokasi Rawan Kecelakaan Jalan Tol Tangerang-Merak
}

\author{
Yogi Oktopianto*1, Sindy Pangesty ${ }^{2}$ \\ ${ }^{12}$ Program Studi Manajemen Keselamatan Transportasi Jalan \\ Politeknik Keselamatan Transportasi Jalan \\ E-mail: *yogi.oktopianto@pktj.ac.id
}

Received 09-02-2021; Reviewed 08-03-2021; Accepted 16-03-2021

Journal Homepage: http://ktj.pktj.ac.id/index.php/ktj

DOI: $10.46447 / \mathrm{ktj} . \mathrm{v} 8 \mathrm{i} 1.301$

\begin{abstract}
Abstrak
Jalan tol sebagai jalan bebas hambatan memiliki perbedaan dari jalan biasa. Namun dengan status bebas hambatan bukan berarti masalah kecelakaan lalu lintas juga dapat teratasi. Jalan tol dirancang dengan tingkat kenyamanan, kelancaran dan keselamatan tinggi, tetapi jumlah kecelakaan di jalan tol Indonesia masih tinggi. Pada ruas jalan tol Tengerang-Merak terdapat 650 kasus kecelakaan dengan fatalitas yang mengakibatkan 31 orang meninggal dunia. Penelitian dilakukan untuk mengidentifikasi daerah rawan kecelakaan (black site) dan lokasi rawan kecelakaan (black spot) pada ruas jalan tol Tengerang-Merak. Metode yang digunakan dalam penelitian ini meliputi metode Angka Ekivalen Kecelakaan (AEK) dan Upper Control Limit (UCL). Hasil penelitian menunjukkan kecelakaan tertinggi pada ruas Jalan Tol Tangerang-Merak berdasarkan perhitungan dengan menggunakan metode Angka Ekivalen Kecelakaan (AEK) per $1 \mathrm{KM}$ yaitu jalur $\mathrm{A}$ di KM 65+000 - 66+000 dan Jalur B KM 40+000 - 41+000. Kemudian menggunakan metode Upper Control Limit (UCL) per $1 \mathrm{KM}$ yaitu jalur A KM 94+000 - 95+000 dan Jalur B KM 97+000 - 98+000. Rekomendasi penanganan lokasi rawan kecelakaan pada ruas Jalan Tol Tangerang-Merak dengan peningkatan kondisi marka dan rambu yang kurang jelas serta penambahan dan perbaikan fasilitas perlengkapan jalan.
\end{abstract}

Kata kunci: Black Site, Black Spot, Equivalent Accident Number, Accident, Jalan Tol

\section{PENDAHULUAN}

Ruas Jalan Tol Tangerang-Merak merupakan salah satu ruas jalan tol yang tedapat di Indonesia. Jalan tol tersebut memiliki panjang ruas $72,45 \mathrm{~km}$ dengan daerah operasional Tangerang hingga Pelabuhan Merak. Ruas jalan tol Tangerang-Merak dibawah PT. Marga Mandalasakti Astra Infra Toll Road merupakan urat nadi transportasi di Jawa dan Sumatera karena masyarakat melakukan perpindahan baik dari maupun masuk ke Pulau Jawa di penyeberangan Pelabuhan Merak. Dampak yang terjadi yaitu adanya peningkatan kepadatan arus yang akan mengakibatkan kemacetan, kecelakaan lalu lintas, antrian di gerbang tol maupun di tempat istirahat dan pelayanan.

Peningkatan kendaraan yang melewati ruas jalan tol Tangerang Merak akan berpengaruh terhadap kecelakaan lalu lintas. Menurut data yang didapatkan dari PT. Marga Mandalasakti Astra Infra Toll Road, terdapat 650 kasus kecelakaan dengan fatalitas yang mengakibatkan 31 orang meninggal dunia. Hal ini tentunya menjadi perhatian penting yang harus dilakukan untuk dapat meningkatkan 
keselamatan dan menurunkan fatalitas akibat kecelakaan lalu lintas. Kecelakaan lalu lintas merupakan salah satu masalah, khususnya pada jalan tol. Dikarenakan jalan tol dirancang sebagai jalan bebas hambatan dengan tingkat kenyamanan, kelancaran dan keselamatan tinggi, tetapi jumlah kecelakaan di jalan tol Indonesia masih tinggi (Darmawan \& Arifin, 2020). Salah satu yang dapat dilakukan adalah analisis daerah rawan kecelakaan. Kegiatan ini dilakukan untuk mengidentifikasi potensi permasalahan keselamatan bagi pengguna jalan serta pemetaan daerah rawan kecelakaan agar dapat mengusulkan strategi pencegahan kecelakaan lalu lintas dengan suatu pendekatan perbaikan terhadap beberapa kondisi desain geometri, bangunan pelengkap jalan, kondisi lingkungan, dan fasilitas pendukung jalan yang berpotensi mengakibatkan konflik lalu lintas bahkan kecelakaan lalu lintas.

Keselamatan jalan raya di era yang semakin modern ini merupakan salah satu masalah yang penting untuk diperhatikan. Peningkatan jumlah kendaraan yang beroperasi di jalan tidak seimbang dengan peningkatan kesadaran dalam berkendara sehingga semakin memperparah masalah transportasi (Rahmawaty et al., 2020). Dengan pesatnya perkembangan ekonomi dan urbanisasi, jumlah kendaraan bermotor perkotaan terus meningkat. Perjalanan perkotaan memang lebih nyaman, tetapi masalah keselamatan lalu lintas semakin menonjol (Fan et al., 2019). Namun hal ini tidaklah sederhana, karena dalam sistem transportasi jalan raya melibatkan tiga unsur utama yaitu manusia, sarana transportasi dan prasarana transportasi (Hidayat \& Oktopianto, 2020).

Penentuan daerah rawan kecelakaan lalu lintas dapat menggunakan metode seperti Angka Ekivalen Kecelakaan (AEK) dan Upper Control Limit (UCL). Karakteristik daerah rawan kecelakaan (black site) dan titik rawan kecelakaan (black spot) lalu lintas dipengaruhi oleh geometrik jalan, volume lalu lintas, kapasitas jalan, dan rambu lalu lintas(Isa Al Qurni, 2016). Informasi mengenai daerah rawan kecelakaan sangat dibutuhkan oleh masyarakat dan penegak hukum. Informasi tersebut dapat dijadikan bahan pertimbangan untuk pengawasan maupun tindakan antisipasi khususnya bagi kepolisian (Arumsari et al., 2016).

Salah satu penyebab utama kecelakaan lalu lintas adalah perilaku mengemudi yang dipengaruhi oleh kondisi lalu lintas dan parameter infrastruktur lainnya (Gregoriades \& Mouskos, 2013). Kecelakaan lalu lintas jalan raya disebabkan oleh beberapa faktor yang berhubungan dengan sistem lalu lintas yaitu pengguna jalan raya, lingkungan jalan raya dan kendaraan. Temuan pada penelitian sebelumnya menunjukkan bahwa pejalan kaki merupakan korban tertinggi dalam jumlah korban tewas atau terluka parah, diikuti oleh penumpang dan pengemudi (W/Yohannes \& Minale, 2015). Oleh karena itu, agar efektif sebagai salah satu tindakan penanggulangan keselamatan mendatang, metode tersebut harus mengintegrasikan pertimbangan dari rekayasa lalu lintas, psikologi pengemudi, dan perilaku kendaraan. Metode manajemen keselamatan lalu lintas terintegrasi dengan mekanisme yang dapat melacak kejadian kecelakaan, bagaimana kendaraan berperilaku dan terakhir risiko kecelakaan apa yang meningkat sebagai rangkaian kejadian (Wakabayashi et al., 2014). Identifikasi ruas jalan dengan kecelakaan berisiko tinggi adalah langkah pertama untuk setiap proses manajemen keselamatan jalan (Ghadi \& Török, 2017).

Kecelakaan lalu lintas disebabkan oleh kesalahan manusia 66,67\%, 
kegagalan kendaraan $11,11 \%$ dan, buruknya kondisi teknis jalan eksisting $22,22 \%$. Setelah menerapkan 3 strategi yang meliputi mendidik pengguna jalan, meningkatkan strategi jalan yang lebih aman, dan meningkatkan keselamatan jalan dan spesifikasi teknis, angka kecelakaan menurun hingga $50 \%$ (Sandhyavitri et al., 2017). Untuk kepentingan penanggulangannya diperlukan adanya suatu pola yang dapat menggambarkan karakteristik proses kejadian suatu kecelakaan lalu lintas, agar dapat disimpulkan faktor penyebabnya supaya dapat dirumuskan pula upaya penanggulangannya, seperti penelitian sebelumnya hasil analisa didapatkan faktor-faktor kecelakaan pada ruas jalan By-Pass Krian - Balongbendo adalah faktor manusia $(79,91 \%)$, faktor kendaraan $(12,66 \%)$, faktor jalan (4,37 \%) dan faktor lingkungan (3,06 \%) (Utomo, 2012).

Faktor dominan kecelakaan yaitu disebabkan oleh manusia. Tindakan yang dapat dilakukan untuk mengurangi kecelakaan pada lokasi titik rawan kecelakaan yaitu dengan membandingkan kondisi ruas jalan yang rawan kecelakaan dengan ruas jalan tingkat kecelakaan rendah, sehingga dapat diambil tindakan teknis. Solusi mengurangi kecelakaan dengan pemasangan rambu, rumble strip dan perbaikan jalanan (Khomeini \& Taufik, 2017).

Jalan tol sebagai jalan bebas hambatan memberikan perbedaan yang nyata dengan jalan biasa. Perbedaan ini diharapkan mampu memberikan kualitas yang lebih mengingat tingkat mobilitas masyarakat yang semakin meningkat. Namun dengan statusnya yang bebas hambatan bukan berarti masalah kecelakaan lalu lintas juga dapat teratasi. Oleh karena itu diperlukan berbagai upaya untuk meminimalkan kemungkinan terjadi kecelakaan (Fahza \& Widyastuti, 2019). Masalah kecelakaan lalu lintas menjadi suatu hal yang vital yang perlu dilakukan kajian terhadapnya, baik mengenai penyebab, akibat, dan penanganannya (Oktopianto et al., 2021). Tujuan dari penelitian ini untuk mengidentifikasi lokasi rawan kecelakaan yang berupa titik rawan kecelakaan lalu lintas ruas Jalan Tol Tangerang-Merak.

\section{METODE}

Lokasi penelitian ini di lakukan pada ruas Jalan Tol Tangerang-Merak yang dikelola oleh PT. Marga Mandalasakti Astra Infra Toll Road. Penelitian ini menggunakan penelitian kuantitatif dengan mendapatkan data melalui data primer dan sekunder yang digunakan sebagai bahan analisis data. Tahapan yang dilakukan dalam penelitian ini adalah:

1. Studi literatur, yaitu untuk melakukan tinjauan terkait identifikasi lokasi rawan kecelakaan yang berupa titik rawan kecelakaan lalu lintas

2. Pengumpulan data, pengumpulan data meliputi data primer yang merupakan data yang langsung didapatkan di lapangan dan data sekunder yang merupakan data yang didapatkan dari sumber. Data primer dan data sekunder dalam penelitian ini yaitu:

a. Data primer meliputi Survei inventarisasi jalan dilakukan dengan maksud untuk mengetahui kondisi ruas jalan di wilayah studi. Kondisi yang diamati adalah meliputi Panjang ruas, lebar, perkerasan jalan, fasilitas dan perlengkapan jalan yang ada seperti rambu dan marka jalan.

b. Data sekunder yaitu berupa data dari PT. Marga Mandalasakti Astra Infra Toll Road yang terdiri dari data geometri jalan, data kinerja lalu lintas, data program penanganan pasca kecelakaan lalu lintas, data kecelakaan lalu 
lintas, standar operasional prosedur, standar pelayanan minimal, dan data fasilitas perlengkapan jalan.

3. Analisis data, yaitu meliputi analisis penentuan daerah rawan kecelakaan menggunakan metode Angka Ekivalen Kecelakaan (AEK) dan Upper Control Limit (UCL).

4. Analisis lokasi rawan kecelakan per STA.

5. Kondisi inventarisasi titik rawan kecelakaan

6. Analisis penyebab kecelakaan

7. Rekomendasi penanganan titik rawan kecelakaan.

\section{HASIL DAN PEMBAHASAN}

Analisis AEK

Metode ini merupakan salah satu metode untuk menghitung angka kecelakaan dengan pembobotan angka yang dihitung dengan menjumlahkan kejadian kecelakaan pada setiap kilometer panjang jalan, kemudian dikalikan dengan nilai bobot sesuai tingkat keparahan. Nilai bobot standar yang digunakan adalah meninggal dunia $(M D)=12$, luka berat $(L B)=3$, luka ringan $(\mathrm{LR})=3$, kerusakan kendaraan $(\mathrm{K})=1$. Penentuan lokasi rawan kecelakaan dihitung dengan pembagian segmen antar gerbang tol. Hasil perhitungan per segmen Jalur A Tahun 2019 dapat dilihat pada tabel 1.

Tabel 1. Lokasi Rawan Kecelakaan Jalur A

\begin{tabular}{|c|c|c|c|c|c|c|c|c|}
\hline \multirow[t]{2}{*}{ No } & \multirow[t]{2}{*}{$\begin{array}{c}\text { Antar } \\
\text { Gerbang } \\
\text { Tol }\end{array}$} & \multirow[t]{2}{*}{$\begin{array}{c}\text { Panjang } \\
(\mathbf{k m})\end{array}$} & \multicolumn{3}{|c|}{$\begin{array}{c}\text { TOTAL } \\
\text { KORBAN }\end{array}$} & \multirow[t]{2}{*}{$\begin{array}{c}\text { Jumlah } \\
\text { AEK }\end{array}$} & \multirow[t]{2}{*}{ BKA } & \multirow[t]{2}{*}{ Kriteria } \\
\hline & & & MD & LB & LR & & & \\
\hline 1 & Cibitung-Cikupa & 5 & 0 & 10 & 20 & 91 & 142,3784737 & $\begin{array}{l}\text { Bukan } \\
\text { Blacklink }\end{array}$ \\
\hline 2 & Cikupa-Baltim & 5 & 1 & 8 & 18 & 91 & 142,3784737 & $\begin{array}{l}\text { Bukan } \\
\text { Blacklink }\end{array}$ \\
\hline 3 & Baltim-Balbar & 3 & 1 & 0 & 4 & 25 & 142,3784737 & $\begin{array}{l}\text { Bukan } \\
\text { Blacklink }\end{array}$ \\
\hline 4 & Balbar-Cikande & 13 & 3 & 9 & 34 & 166 & 142,3784737 & Blacklink \\
\hline 5 & Cikande-Ciujung & 8 & 3 & 8 & 15 & 106 & 142,3784737 & $\begin{array}{l}\text { Bukan } \\
\text { Blacklink }\end{array}$ \\
\hline 6 & Ciujung-Sertim & 12 & 6 & 18 & 71 & 340 & 142,3784737 & Blacklink \\
\hline 7 & Sertim-Serbar & 6 & 0 & 11 & 5 & 49 & 142,3784737 & $\begin{array}{l}\text { Bukan } \\
\text { Blacklink }\end{array}$ \\
\hline 8 & Serbar-Ciltim & 9 & 5 & 9 & 23 & 157 & 142,3784737 & Blacklink \\
\hline 9 & Ciltim-Cilbar & 7 & 1 & 5 & 4 & 40 & 142,3784737 & $\begin{array}{l}\text { Bukan } \\
\text { Blacklink }\end{array}$ \\
\hline 10 & Cilbar-Merak & 4 & 1 & 3 & 7 & 43 & 142,3784737 & $\begin{array}{l}\text { Bukan } \\
\text { Blacklink }\end{array}$ \\
\hline
\end{tabular}

Sumber: Hasil Analisis, 2020

Berdasarkan hasil perhitungan menggunakan metode AEK, diperoleh bahwa pada jalur A ditemukan terdapat 3 segmen yang teridentifikasi lokasi rawan kecelakaan (blacklink), yaitu pada segmen Balaraja Barat-Cikande, segmen Ciujung-Serang Timur, dan segmen Serang Barat-Cilegon Timur dengan segmen paling tinggi pada Ciujung-Serang Timur. Hasil perhitungan lokasi rawan kecelakaan per segmen Jalur B Tahun 2019 dapat dilihat pada tabel 2. 
Tabel 2. Lokasi Rawan Kecelakaan Jalur B

\begin{tabular}{|c|c|c|c|c|c|c|c|c|}
\hline \multirow[t]{2}{*}{ No } & \multirow{2}{*}{$\begin{array}{c}\text { Antar } \\
\text { Gerbang } \\
\text { Tol } \\
\end{array}$} & \multirow{2}{*}{$\begin{array}{c}\text { Panjang } \\
(\mathbf{k m})\end{array}$} & \multicolumn{3}{|c|}{$\begin{array}{c}\text { TOTAL } \\
\text { KORBAN }\end{array}$} & \multirow{2}{*}{$\begin{array}{c}\text { Jumlah } \\
\text { AEK }\end{array}$} & \multirow[t]{2}{*}{ BKA } & \multirow[t]{2}{*}{ Kriteria } \\
\hline & & & MD & LB & LR & & & \\
\hline 1 & Cibitung-Cikupa & 5 & 0 & 0 & 11 & 34 & 67,810677 & $\begin{array}{l}\text { Bukan } \\
\text { Blacklink }\end{array}$ \\
\hline 2 & Cikupa-Baltim & 5 & 2 & 3 & 8 & 58 & 67,810677 & $\begin{array}{l}\text { Bukan } \\
\text { Blacklink }\end{array}$ \\
\hline 3 & Baltim-Balbar & 3 & 0 & 0 & 0 & 1 & 67,810677 & $\begin{array}{l}\text { Bukan } \\
\text { Blacklink }\end{array}$ \\
\hline 4 & Balbar-Cikande & 13 & 3 & 7 & 12 & 94 & 67,810677 & Blacklink \\
\hline 5 & Cikande-Ciujung & 8 & 1 & 5 & 24 & 100 & 67,810677 & Blacklink \\
\hline 6 & Ciujung-Sertim & 12 & 2 & 3 & 12 & 70 & 67,810677 & Blacklink \\
\hline 7 & Sertim-Serbar & 6 & 0 & 2 & 11 & 40 & 67,810677 & $\begin{array}{l}\text { Bukan } \\
\text { Blacklink }\end{array}$ \\
\hline 8 & Serbar-Ciltim & 9 & 2 & 8 & 6 & 67 & 67,810677 & $\begin{array}{l}\text { Bukan } \\
\text { Blacklink }\end{array}$ \\
\hline 9 & Ciltim-Cilbar & 7 & 0 & 0 & 1 & 4 & 67,810677 & $\begin{array}{l}\text { Bukan } \\
\text { Blacklink }\end{array}$ \\
\hline 10 & Cilbar-Merak & 4 & 0 & 1 & 0 & 4 & 67,810677 & $\begin{array}{l}\text { Bukan } \\
\text { Blacklink }\end{array}$ \\
\hline
\end{tabular}

Sumber: Hasil Analisis, 2020

Berdasarkan hasil perhitungan menggunakan metode AEK, pada jalur B terdapat 3 segmen yang teridentifikasi sebagai lokasi rawan kecelakaan (blacklink) yaitu segmen Balaraja Barat- Cikande, segmen Cikande-Ciujung, dan segmen Ciujung-Serang Timur. Dari hasil analisis, diperoleh hasil bahwa segmen yang memiliki AEK paling tinggi pada jalur B Tahun 2019 adalah segmen CikandeCiujung. Namun, dengan mempertimbangkan fatalitas korban kecelakaan, maka lokasi rawan kecelakaan yang akan dilakukan analisis lebih lanjut adalah segmen dengan jumlah korban meninggal dunia paling tinggi dan teridentifikasi blacklink yaitu Balaraja Barat-Cikande dengan 3 jumlah korban meninggal dunia.

\section{Kapasitas Ruas Jalan Balaraja Barat-Cikande}

Lebar jalur lalu lintas : 3 × 3,6 meter

Tipe jalan :6/2 D

Setelah faktor penyesuaian kapasitas jalan bebas hambatan ditentukan, maka kapasitas ruas jalan Balaraja Barat-Cikande adalah seperti pada tabel 3.

Tabel 3. Kapasitas Jalan Balaraja Barat-Cikande

\begin{tabular}{cccccc}
\hline Jalur & $\begin{array}{c}\text { Lebar } \\
\text { Lajur } \\
\mathbf{( m )}\end{array}$ & $\begin{array}{c}\text { Jumlah } \\
\text { Lajur }\end{array}$ & $\begin{array}{c}\text { Kapasitas } \\
\text { Dasar } \\
\mathbf{( C o )}\end{array}$ & FCw & $\begin{array}{c}\text { Kapasitas (C) } \\
\text { Smp/jam }\end{array}$ \\
\hline A & 3,6 & 3 & 2.300 & 1 & $3 \times 2.300=6.900$ \\
B & 3,6 & 3 & 2.300 & 1 & $3 \times 2.300=6.900$ \\
\hline
\end{tabular}

Sumber: Hasil Analisis, 2020 
Berdasarkan hasil perhitungan, kapasitas jalan Balaraja Barat - Cikande menunjukkan pada jalur A maupun jalur B adalah $6.900 \mathrm{smp} / \mathrm{jam}$.

\section{Lokasi Rawan Kecelakan per STA}

Lokasi Rawan Kecelakaan Jalur A Tahun 2019 Pada Segmen Ciujung-Serang Timur. Lokasi rawan kecelakaan pada Jalan Tol Tangerang-Merak ditentukan berdasarkan per 1 kilometer pada setiap lajurnya. Hasil perhitungan lokasi rawan kecelakaan pada segmen Ciujung-Serang Timur jalur A dapat dilihat pada tabel 4.

Tabel 4. Lokasi Rawan Kecelakaan pada segmen Ciujung-Serang Timur Jalur

\begin{tabular}{|c|c|c|c|c|c|c|c|c|}
\hline \multirow{2}{*}{ No } & \multirow{2}{*}{ STA } & \multirow{2}{*}{$\begin{array}{c}\text { Panjang } \\
\text { (km) }\end{array}$} & \multicolumn{3}{|c|}{$\begin{array}{c}\text { TOTAL } \\
\text { KORBAN }\end{array}$} & \multirow{2}{*}{$\begin{array}{l}\text { Jumlah } \\
\text { AEK }\end{array}$} & \multirow[t]{2}{*}{ BKA } & \multirow[t]{2}{*}{ Kriteria } \\
\hline & & & MD & LB & LR & & & \\
\hline 1 & $\begin{array}{l}60+000- \\
61+000\end{array}$ & 1 & 1 & 2 & 10 & 49 & 45,47498074 & Blackspot \\
\hline 2 & $\begin{array}{l}61+000- \\
62+000\end{array}$ & 1 & 0 & 1 & 1 & 7 & 45,47498074 & $\begin{array}{l}\text { Bukan } \\
\text { Blackspot }\end{array}$ \\
\hline 3 & $\begin{array}{l}62+000- \\
63+000\end{array}$ & 1 & 0 & 0 & 2 & 7 & 45,47498074 & $\begin{array}{l}\text { Bukan } \\
\text { Blackspot }\end{array}$ \\
\hline 4 & $\begin{array}{l}63+000- \\
64+000\end{array}$ & 1 & 1 & 3 & 1 & 25 & 45,47498074 & $\begin{array}{l}\text { Bukan } \\
\text { Blackspot }\end{array}$ \\
\hline 5 & $\begin{array}{l}64+000- \\
65+000\end{array}$ & 1 & 0 & 1 & 3 & 13 & 45,47498074 & $\begin{array}{l}\text { Bukan } \\
\text { Blackspot }\end{array}$ \\
\hline 6 & $\begin{array}{l}65+000- \\
66+000\end{array}$ & 1 & 2 & 2 & 13 & 70 & 45,47498074 & Blackspot \\
\hline 7 & $\begin{array}{l}66+000- \\
67+000\end{array}$ & 1 & 1 & 1 & 7 & 37 & 45,47498074 & $\begin{array}{l}\text { Bukan } \\
\text { Blackspot }\end{array}$ \\
\hline 8 & $\begin{array}{l}67+000- \\
68+000\end{array}$ & 1 & 0 & 1 & 5 & 19 & 45,47498074 & $\begin{array}{l}\text { Bukan } \\
\text { Blackspot }\end{array}$ \\
\hline 9 & $\begin{array}{l}68+000- \\
69+000\end{array}$ & 1 & 0 & 1 & 6 & 22 & 45,47498074 & $\begin{array}{l}\text { Bukan } \\
\text { Blackspot }\end{array}$ \\
\hline 10 & $\begin{array}{l}69+000- \\
70+000\end{array}$ & 1 & 1 & 2 & 8 & 43 & 45,47498074 & $\begin{array}{l}\text { Bukan } \\
\text { Blackspot }\end{array}$ \\
\hline 11 & $\begin{array}{l}70+000- \\
71+000\end{array}$ & 1 & 0 & 2 & 7 & 28 & 45,47498074 & $\begin{array}{l}\text { Bukan } \\
\text { Blackspot }\end{array}$ \\
\hline 12 & $\begin{array}{l}71+000- \\
72+000\end{array}$ & 1 & 0 & 2 & 8 & 31 & 45,47498074 & $\begin{array}{l}\text { Bukan } \\
\text { Blackspot }\end{array}$ \\
\hline
\end{tabular}

Sumber: Hasil Analisis, 2020

Berdasarkan hasil perhitungan menggunakan metode AEK, diperoleh bahwa terdapat 2 titik yang teridentifikasi sebagai lokasi rawan kecelakaan (blackspot) yaitu pada STA $60+000-61+000$ dan STA 65+000 - 66+000. Dari hasil analisis, diperoleh hasil bahwa titik yang memiliki AEK paling tinggi pada jalur A Segmen Ciujung-Serang Timur Tahun 2019 adalah STA 65+000$66+000$.

Lokasi Rawan Kecelakaan Pada Segmen Balaraja Barat-Cikande Jalur B Tahun 2019 pada Jalan Tol Tangerang-Merak dapat dilihat pada tabel 5. 
Tabel 5. Lokasi Rawan Kecelakaan pada Segmen Balaraja Barat-Cikande

\begin{tabular}{|c|c|c|c|c|c|c|c|c|}
\hline \multirow[b]{2}{*}{ No } & \multirow[b]{2}{*}{ STA } & \multirow{2}{*}{$\begin{array}{l}\text { Panjang } \\
\text { (km) }\end{array}$} & \multicolumn{3}{|c|}{ TOTAL KORBAN } & \multirow{2}{*}{$\begin{array}{c}\text { Jumlah } \\
\text { AEK }\end{array}$} & \multirow[b]{2}{*}{ BKA } & \multirow[b]{2}{*}{ Kriteria } \\
\hline & & & MD & LB & LR & & & \\
\hline 1 & $\begin{array}{l}39+000- \\
40+000\end{array}$ & 1 & 1 & 0 & 2 & 19 & 16,720328 & Blackspot \\
\hline 2 & $\begin{array}{l}40+000- \\
41+000\end{array}$ & 1 & 2 & 0 & 0 & 25 & 16,720328 & Blackspot \\
\hline 3 & $\begin{array}{l}41+000- \\
42+000\end{array}$ & 1 & 0 & 0 & 0 & 1 & 16,720328 & $\begin{array}{l}\text { Bukan } \\
\text { Blackspot }\end{array}$ \\
\hline 4 & $\begin{array}{l}42+000- \\
43+000\end{array}$ & 1 & 0 & 0 & 0 & 1 & 16,720328 & $\begin{array}{l}\text { Bukan } \\
\text { Blackspot }\end{array}$ \\
\hline 5 & $\begin{array}{l}43+000- \\
44+000\end{array}$ & 1 & 0 & 0 & 0 & 1 & 16,720328 & $\begin{array}{l}\text { Bukan } \\
\text { Blackspot }\end{array}$ \\
\hline 6 & $\begin{array}{l}44+000- \\
45+000\end{array}$ & 1 & 0 & 1 & 0 & 4 & 16,720328 & $\begin{array}{l}\text { Bukan } \\
\text { Blackspot }\end{array}$ \\
\hline 7 & $\begin{array}{l}45+000- \\
46+000\end{array}$ & 1 & 0 & 0 & 1 & 4 & 16,720328 & $\begin{array}{l}\text { Bukan } \\
\text { Blackspot }\end{array}$ \\
\hline 8 & $\begin{array}{l}46+000- \\
47+000\end{array}$ & 1 & 0 & 1 & 5 & 19 & 16,720328 & Blackspot \\
\hline 9 & $\begin{array}{l}47+000- \\
48+000\end{array}$ & 1 & 0 & 2 & 1 & 10 & 16,720328 & $\begin{array}{l}\text { Bukan } \\
\text { Blackspot }\end{array}$ \\
\hline 10 & $\begin{array}{l}48+000- \\
49+000\end{array}$ & 1 & 0 & 0 & 0 & 1 & 16,720328 & $\begin{array}{l}\text { Bukan } \\
\text { Blackspot }\end{array}$ \\
\hline 11 & $\begin{array}{l}49+000- \\
50+000\end{array}$ & 1 & 0 & 1 & 2 & 10 & 16,720328 & $\begin{array}{l}\text { Bukan } \\
\text { Blackspot }\end{array}$ \\
\hline 12 & $\begin{array}{l}50+000- \\
51+000\end{array}$ & 1 & 0 & 0 & 0 & 1 & 16,720328 & $\begin{array}{l}\text { Bukan } \\
\text { Blackspot }\end{array}$ \\
\hline 13 & $\begin{array}{l}51+000- \\
52+000\end{array}$ & 1 & 0 & 2 & 1 & 10 & 16,720328 & $\begin{array}{l}\text { Bukan } \\
\text { Blackspot }\end{array}$ \\
\hline
\end{tabular}

Sumber: Hasil Analisis, 2020

Berdasarkan hasil perhitungan menggunakan metode AEK, pada Segmen Balaraja Barat-Cikande Jalur B diperoleh bahwa terdapat 3 titik yang teridentifikasi sebagai lokasi rawan kecelakaan (blackspot) yaitu pada STA 39+000 - 40+000, STA 40+000 - 41+000 dan STA 46+000 - 47+000. Dari hasil analisis, diperoleh hasil bahwa titik yang memiliki AEK paling tinggi pada jalur $B$ segmen Balaraja Barat-Cikande adalah STA 40+000-41+000.

\section{Analisis Upper Control Limit (UCL)}

Upper Control Limit (UCL) merupakan salah satu metode yang dapat digunakan untuk menentukan lokasi rawan kecelakaan. Lokasi rawan kecelakaan dapat diidentifikasi pada lokasi tertentu (black spot) atau ruas jalan tertentu (black link). Lokasi rawan kecelakaan ditentukan jika tingkat kecelakaan pada ruas jalan tertentu melewati batas normal dimana batas normal yang dimaksud adalah Upper Control Limit.

Hasil perhitungan menujukkan lokasi rawan kecelakaan per segmen menggunakan metode Upper Control Limit (UCL) pada Jalur A dapat dilihat pada tabel 6. 
Tabel 6. Lokasi Rawan Kecelakaan Metode UCL Jalur A

\begin{tabular}{|c|c|c|c|c|c|c|}
\hline $\begin{array}{l}\text { Antar } \\
\text { Gerbang }\end{array}$ & $\begin{array}{l}\text { Panjang } \\
\text { Jalan } \\
\text { (KM) }\end{array}$ & LHR & FK & TK & UCL & KET \\
\hline Cibitung-Cikupa & 5 & $53.752,58$ & 33 & 33,5478 & 72,15306 & $\begin{array}{l}\text { Bukan } \\
\text { Blacklink }\end{array}$ \\
\hline Cikupa-Baltim & 5 & $45.104,70$ & 21 & 25,4417 & 72,15306 & $\begin{array}{l}\text { Bukan } \\
\text { Blacklink }\end{array}$ \\
\hline Baltim-Balbar & 3 & $37.425,78$ & 13 & 31,6352 & 73,87162 & $\begin{array}{l}\text { Bukan } \\
\text { Blacklink }\end{array}$ \\
\hline Balbar-Cikande & 13 & $30.890,87$ & 61 & 41,5026 & 72,64684 & $\begin{array}{l}\text { Bukan } \\
\text { Blacklink }\end{array}$ \\
\hline Cikande-Ciujung & 8 & $28.973,35$ & 71 & 83,6929 & 71,71387 & Blacklink \\
\hline Ciujung-Sertim & 12 & $27.283,70$ & 119 & 99,3073 & 72,37912 & Blacklink \\
\hline Sertim-Serbar & 6 & $22.766,34$ & 30 & 60,0061 & 71,84453 & $\begin{array}{l}\text { Bukan } \\
\text { Blacklink }\end{array}$ \\
\hline Serbar-Ciltim & 9 & $20.496,92$ & 52 & 77,0178 & 71,79713 & Blacklink \\
\hline Ciltim-Cilbar & 7 & $13.241,12$ & 16 & 47,1646 & 71,71788 & $\begin{array}{l}\text { Bukan } \\
\text { Blacklink }\end{array}$ \\
\hline Cilbar-Merak & 4 & $8.382,54$ & 13 & 105,9319 & 72,75238 & Blacklink \\
\hline
\end{tabular}

Sumber: Hasil Analisi, 2020

Berdasarkan hasil perhitungan menggunakan metode Upper Control Limit (UCL) diperoleh bahwa pada jalur A tahun 2019 segmen yang teridentifikasi sebagai lokasi rawan kecelakaan (blacklink) yaitu pada segmen Cikande-Ciujung, segmen Ciujung-Serang Timur, segmen Serang Barat-Cilegon Timur, dan segmen Cilegon Barat-Merak.

Tabel 7. Lokasi Rawan Kecelakaan Metode UCL Jalur B

\begin{tabular}{lcccccl}
\hline $\begin{array}{c}\text { Antar } \\
\text { Gerbang }\end{array}$ & $\begin{array}{c}\text { Panjang } \\
\text { Jalan } \\
\text { (KM) }\end{array}$ & LHR & FK & TK & UCL & \multicolumn{1}{c}{ KET } \\
\hline Cibitung-Cikupa & 5 & $52.723,95$ & 9 & 9,3534 & 41,66052 & $\begin{array}{l}\text { Bukan } \\
\text { Blacklink }\end{array}$ \\
Cikupa-Baltim & 5 & $44.623,93$ & 26 & 31,9259 & 41,66052 & $\begin{array}{l}\text { Bukan } \\
\text { Blacklink } \\
\text { Bukan }\end{array}$ \\
Baltim-Balbar & 3 & $35.604,68$ & 6 & 15,3897 & 42,68022 & $\begin{array}{l}\text { Blacklink } \\
\text { Bukan }\end{array}$ \\
Balbar-Cikande & 13 & $30.446,28$ & 47 & 32,5332 & 43,0665 & $\begin{array}{l}\text { Blacklink } \\
\text { Bukan }\end{array}$ \\
Cikande-Ciujung & 8 & $28.704,24$ & 33 & 39,3718 & 41,7243 & $\begin{array}{l}\text { Blacklink } \\
\text { Bukan }\end{array}$ \\
Ciujung-Sertim & 12 & $26.556,56$ & 49 & 42,126 & 42,73796 & $\begin{array}{l}\text { Blacklink } \\
\text { Bukan }\end{array}$ \\
Sertim-Serbar & 6 & $21.692,58$ & 15 & 31,5745 & 41,56124 & $\begin{array}{l}\text { Blacklink } \\
\text { Blacklink }\end{array}$ \\
Serbar-Ciltim & 9 & $20.010,79$ & 28 & 42,595 & 41,91615 & $\begin{array}{l}\text { Bukan } \\
\text { Ciltim-Cilbar }\end{array}$ \\
Cilbar-Merak & 7 & $12.696,05$ & 7 & 21,5794 & 41,59723 & $\begin{array}{l}\text { Blacklink } \\
\text { Blacklink }\end{array}$ \\
\hline
\end{tabular}

Sumber: Hasil Analisis, 2020 
Berdasarkan hasil perhitungan menggunakan metode Upper Control Limit (UCL) diperoleh bahwa pada jalur B terdapat 2 segmen yang teridentifikasi sebagai lokasi rawan kecelakaan (black link) yaitu segmen Serang Barat-Cilegon Timur, dan segmen Cilegon Barat-Merak. Dari 2 segmen yang teridentifikasi sebagai lokasi rawan kecelakaan (black link) tertinggi adalah segmen Cilegon BaratMerak.

\section{Lokasi Rawan Kecelakaan per STA}

Pada jalur A dari 4 segmen yang teridentifikasi sebagai lokasi rawan kecelakaan (black link) tertinggi adalah segmen Cilegon Barat-Merak. Lokasi rawan kecelakaan ditentukan berdasarkan per 1 kilometer pada setiap lajurnya. Hasil perhitungan lokasi rawan kecelakaan pada segmen Cilegon Barat-Merak jalur A dapat dilihat pada tabel 8.

Tabel 8. Lokasi Rawan Kecelakaan pada Segmen Cilegon Barat-Merak Jalur A

\begin{tabular}{lcccccc}
\hline STA & $\begin{array}{c}\text { Panjang } \\
\text { Jalan } \\
(\text { KM) }\end{array}$ & LHR & FK & TK & UCL & KET \\
\hline $\begin{array}{l}94+000- \\
95+000\end{array}$ & 1 & $8.382,54$ & 6 & 196,1 & 119,6041 & Blackspot \\
$95+000-$ & 1 & $8.382,54$ & 2 & 65,37 & 119,6041 & Bukan Blackspot \\
$96+000$ & 1 & $8.382,54$ & 3 & 98,05 & 119,6041 & Bukan Blackspot \\
$96+000-$ & 1 & $8.382,54$ & 2 & 65,37 & 119,6041 & Bukan Blackspot \\
$97+000$ & 1 & & & & & \\
$97+000-$ & $98+000$ & &
\end{tabular}

Sumber: Hasil Analisis, 2020

Berdasarkan hasil perhitungan menggunakan metode Upper Control Limit (UCL) diperoleh bahwa pada segmen Cilegon Barat-Merak jalur A tahun 2019 terdapat 1 titik yang teridentifikasi sebagai lokasi rawan kecelakaan (black spot) yaitu STA 94+000-95+000.

Hasil perhitungan lokasi rawan kecelakaan pada segmen Cilegon BaratMerak jalur B dapat dilihat pada tabel 9.

Tabel 9. Lokasi Rawan Kecelakaan pada Segmen Cilegon Barat-Merak Jalur B

\begin{tabular}{rcccccl}
\hline STA & $\begin{array}{c}\text { Panjang } \\
\text { Jalan } \\
\text { (KM) }\end{array}$ & LHR & FK & TK & UCL & KET \\
\hline $\begin{array}{l}94+000- \\
95+000\end{array}$ & 1 & $8.282,15$ & 1 & 33,08 & 66,29438 & Bukan Blackspot \\
\hline $\begin{array}{l}95+000- \\
96+000\end{array}$ & 1 & $8.282,15$ & 0 & 0 & 66,29438 & Bukan Blackspot \\
\hline $96+000-$ & 1 & $8.282,15$ & 0 & 0 & 66,29438 & Bukan Blackspot \\
$97+000$ & 1 & $8.282,15$ & 5 & 165,4 & 66,29438 & Blackspot \\
\hline $97+000-$ & 1 & & & & \\
$98+000$ & & &
\end{tabular}

Sumber: Hasil Analisis, 2020 
Berdasarkan hasil perhitungan menggunakan metode Upper Control Limit (UCL) diperoleh bahwa pada segmen Cilegon Barat-Merak jalur B terdapat 1 titik yang teridentifikasi sebagai lokasi rawan kecelakaan (black spot) yaitu STA 97+000-98+000.

\section{Analisis Penyebab Kecelakaan STA 65+000 - 66+000}

Berdasarkan hasil identifikasi lokasi rawan kecelakaan, Lokasi STA 65+000 - 66+000 menurut data sekunder memiliki karakteristik kecelakaan yaitu kecelakaan tunggal, kendaraan paling banyak terlibat adalah kendaraan minibus, waktu kejadian pukul 15.00-18.00, dan faktor penyebab kecelakaan terbanyak adalah human error/ mengantuk. Selanjutnya berdasarkan data primer pada lokasi tersebut merupakan trek lurus dengan kondisi jalan yang sangat bagus sehingga memungkinkan pengguna jalan mengemudikan kendaraannya dengan cepat. Hasil survey kecepatan menunjukkan bahwa kendaraan golongan 1 memiliki kecepatan presentil-85 adalah $103 \mathrm{~km} / \mathrm{jam}$ yang memiliki arti 85\% kecepatan kendaraan golongan 1 mengemudikan kendaraannya $\geq 103 \mathrm{~km} / \mathrm{jam}$ dan $15 \%$ mengemudikan kendaraannya $\leq 103 \mathrm{~km} / \mathrm{jam}$.

Selain itu berdasarkan data perlengkapan jalan yang diperoleh dilapangan, pada lokasi tersebut ditemukan pagar pengaman/guardrail yang dipasang hanya pada area aset jalan tol dengan ukuran panjang pagar/guardrail yang tidak sesuai pedoman manajemen bahaya sisi jalan yakni minimal 30 meter, serta ditemukan bangunan sisi jalan yang dekat dengan jalur lalu lintas yang memotong panjang guardrail. Beberapa rambu lalu lintas ditemukan dalam kondisi miring dan berkarat yang sewaktu-waktu dapat roboh dan menimbulkan bahaya bagi pengguna jalan. Data temuan di lapangan juga berupa stiker reflektor delineator yang terlepas dari tiang, sehingga fungsi delineator berkurang. Terdapat marka jalan yang ganda dapat membingungkan pengguna jalan saat berada dijalan.

Analisa dari data primer dan sekunder dapat disimpulkan bahwa kejadian kecelakaan lalu lintas dapat disebabkan oleh faktor jalan yang lurus yang memicu pengemudi untuk berkecepatan tinggi. Waktu rawan kecelakaan adalah sore hari dimana banyak pengemudi kendaraan dalam kondisi lelah oleh kegiatan seharihari.

\section{Analisis Penyebab Kecelakaan STA 40+000-41+000}

Dari analisa data sekunder, lokasi rawan kecelakaan di STA 40+000-41+000 memiliki karakteristik kecelakaan yakni kecelakaan tunggal, kendaraan paling banyak terlibat adalah kendaraan truk kecil, waktu rawan kecelakaan adalah pukul 15.00-18.00 WIB, faktor penyebab kecelakaan terbanyak adalah human eror/mengantuk. Berdasarkan data primer pada lokasi tersebut merupakan trek lurus $1 \mathrm{KM}$ mendekati gerbang exit tol Balaraja Barat, dimana kondisi jalannya sangat bagus namun alinyemen vertikalnya berupa tanjakan dan turunan yang memungkinkan pengguna jalan mengemudikan kendaraannya dengan cepat. Hasil survey kecepatan menunjukkan bahwa kendaraan golongan 1 memiliki kecepatan presentil-85 adalah $113 \mathrm{~km} / \mathrm{jam}$ yang memiliki arti bahwa 85\% kendaraan golongan 1 mengemudikan kendaraannya $\geq 113 \mathrm{~km} / \mathrm{jam}$ dan $15 \%$ mengemudikan kendaraannya $\leq 113 \mathrm{~km} / \mathrm{jam}$.

Dari data perlengkapan jalan yang diperoleh dilapangan, pada lokasi tersebut ditemukan sambungan antara median concreate barier (MCB) dengan 
guardrail tidak sesuai dengan pedoman manajemen bahaya sisi jalan. Pemasangan guardrail juga berhimpitan dengan pagar pembatas jalan dan tidak sesuai dengan pedoman manajemen bahaya sisi jalan dikarenakan guardrail memiliki defleksi sehingga diperlukan jarak yang cukup antara guardrail dan pagar pembatas.

Penempatan rambu yang bersebelahan dengan papan reklame dapat membuat pengemudi salah persepsi, bahkan tidak dapat membaca rambu. Selain itu kondisi stiker reflektor delineator ditemukan ada yang terlepas dari tiangnya sehingga pada malam hari pengemudi tidak dapat dipandu oleh keberadaan reflektor sebagai pembatas sisi kiri dan kanan jalan. Kondisi drainase yang dipenuhi dengan rumput membuat air menjadi tersumbat saat kondisi hujan. Dari hasil analisis data primer dan sekunder dapat disimpulkan bahwa kejadian kecelakaan lalu lintas dapat disebabkan oleh faktor jalan lurus yang memicu pengemudi untuk berkecepatan tinggi. Waktu rawan kecelakaan di lokasi tersebut adalah sore hari, dimana merupakan waktu lelah pengemudi. Selain itu perilaku pengemudi yang cenderung mengubah lajur dengan tiba-tiba setelah melihat rambu petunjuk $1 \mathrm{KM}$ menuju gerbang exit Balaraja Barat membuat kaget pengemudi di belakangnya. Kondisi ini dapat membuat pengemudi di belakangnya hilang kendali dan mengakibatkan tabrakan.

\section{SIMPULAN}

Hasil identifikasi lokasi rawan kecelakaan tertinggi pada Ruas Jalan Tol Tangerang-Merak berdasarkan perhitungan data kecelakaan tahun 2019 dengan menggunakan metode Angka Ekivalen Kecelakaan (AEK) per $1 \mathrm{KM}$, yaitu jalur A di KM 65+000-66+000, faktor penyebab kecelakaan terbanyak dikarenakan mengantuk, waktu rawan kecelakaan antara pukul 15.00-18.00 WIB, kendaraan yang paling banyak terlibat adalah minibus dengan tipe kecelakaan paling sering terjadi adalah kecelakaan tunggal. Jalur B KM 40+000-41+000, faktor penyebab kecelakaan tertinggi adalah karena faktor mengantuk pada waktu rawan yaitu antara pukul 15.00-18.00 WIB, kendaraan yang paling banyak terlibat adalah truk kecil dengan tipe kecelakaan adalah kecelakaan tunggal. Kemudian menggunakan metode Upper Control Limit (UCL) per $1 \mathrm{KM}$, yaitu jalur A KM 94+000-95+000, faktor penyebab kecelakaan tertinggi adalah kurang antisipasi pengemudi dan mengantuk, waktu rawan kecelakaan adalah antara pukul 02.00-03.00 WIB, kendaraan paling banyak terlibat adalah kendaraan minibus dengan tipe kecelakaan terbanyak adalah kecelakaan tunggal. Jalur B KM 97+000-98+000, faktor penyebab kecelakaan terbanyak adalah kurang antisipasi, waktu rawan kecelakaan yaitu antara pukul 21.00-24.00 WIB dan 06.00-09.00 WIB, kendaraan paling banyak terlibat adalah truk besar dengan tipe kecelakaan terbanyak adalah kecelakaan tunggal. Rekomendasi penanganan lokasi rawan kecelakaan pada Ruas Jalan Tol Tangerang-Merak yaitu peningkatan kondisi marka dan rambu yang kurang jelas, perbaikan pagar pengaman yang sesuai berdasarkan panduan manajemen bahaya sisi jalan, serta penambahan dan perbaikan fasilitas perlengkapan jalan. 


\section{DAFTAR PUSTAKA}

Arumsari, N. D., Nugraha, A. L., \& Awaluddin, M. (2016). Pemodelan Daerah Rawan Kecelakaan Dengan Menggunakan Cluster Analysis. Geodesi Undip.

Darmawan, A., \& Arifin, Z. N. (2020). DI JALAN TOL JAGORAWI. 2(1).

Fahza, A., \& Widyastuti, H. (2019). Analisis Daerah Rawan Kecelakaan Lalu Lintas pada Ruas Jalan Tol Surabaya-Gempol. Jurnal Teknik ITS. https://doi.org/10.12962/j23373539.v8i1.42123

Fan, Z., Liu, C., Cai, D., \& Yue, S. (2019). Research on black spot identification of safety in urban traffic accidents based on machine learning method. Safety Science. https://doi.org/10.1016/j.ssci.2019.05.039

Ghadi, M., \& Török, Á. (2017). Comparison Different Black Spot Identification Methods. Transportation Research Procedia. https://doi.org/10.1016/j.trpro.2017.12.104

Gregoriades, A., \& Mouskos, K. C. (2013). Black spots identification through a Bayesian Networks quantification of accident risk index. Transportation Research Part C: Emerging Technologies. https://doi.org/10.1016/j.trc.2012.12.008

Hidayat, D. W., \& Oktopianto, Y. (2020). Peningkatan Kinerja Simpang Tiga Bersinyal Studi Kasus Simpang Tiga Purin Kendal. Jurnal Keselamatan Transportasi Jalan (Indonesian Journal of Road Safety), 72 , 36-45. https://doi.org/10.46447/ktj.v7i2.289

Isa Al Qurni. (2016). ANALISIS DAERAH RAWAN KECELAKAAN LALU LINTAS (STUDI KASUS JALAN NASIONAL ARTERI PRIMER DAN ARTERI SEKUNDER KABUPATEN KENDAL). Jurnal Geografi: Media Informasi Pengembangan Dan Profesi Kegeografian. https://doi.org/10.15294/jg.v13i1.7989

Khomeini, M., \& Taufik, S. (2017). ANALISIS PENANGANAN LOKASI RAWAN KECELAKAAN LALU LINTAS DI KOTA PALANGKA RAYA. Jurnal Teknologi Berkelanjutan (Sustainable Technology Journal).

Oktopianto, Y., Shofiah, S., Rokhman, F. A., \& Pangestu, K. (2021). Analisis Daerah Rawan Kecelakaan ( Black Site ) Dan Titik Rawan Kecelakaan ( Black Spot ) Provinsi Lampung. Borneo Engineering: Jurnal Teknik Sipil, 5(1), 4051. https://doi.org/10.35334/be.v5i1.1777

Rahmawaty, T. A., Kriswardhana, W., Widiarti, W. Y., \& Sulistyono, S. (2020). Analisis Karakteristik Kecelakaan di Ruas Jalan Gadjah Mada Kabupaten Jember. Borneo Engineering: Jurnal Teknik Sipil, 4(1), 113-125.

Sandhyavitri, A., Zamri, Wiyono, S., \& Subiantoro. (2017). Three Strategies Reducing Accident Rates at Black Spots and Black Sites Road in Riau Province, Indonesia. Transportation Research Procedia.

Utomo, N. (2012). Analisa Faktor Penyebab Kecelakaan Lalu Lintas Pada Segmen Jalan By-Pass Krian-Balongbendo (Km. 26+000-Km. 44+520). Jurnal Teknik Sipil KERN.

W/Yohannes, A. Y., \& Minale, A. S. (2015). Identifying the hot spot areas of road traffic accidents. Jordan Journal of Civil Engineering. https://doi.org/10.14525/jjce.9.3.3077

Wakabayashi, H., Ando, M., Kawaguchi, T., Horie, Y., \& Hotta, K. H. (2014). Sustainable traffic safety management at accident black spots combined with drivers' psychology and vehicle engineering using eye mark recorder. Transportation Research Procedia. https://doi.org/10.1016/j.trpro.2014.10.094 